\title{
PARA UNGULA SOFT TISSUE EXCISION FOR IN GROWING TOE NAIL: A NOVEL METHOD FOR SIMPLE SURGICAL CURE
}

\author{
Aswini Kumar Pujahari1 ${ }^{1}$ Aparajita Mookharjee ${ }^{2}$
}

${ }_{1}^{1}$ Professor, Department of General Surgery, Vydehi Institute of Medical Sciences and Research Center, Bangalore.

${ }^{2}$ Associate Professor, Department of General Surgery, Vydehi Institute of Medical Sciences and Research Center, Bangalore.

ABSTRACT: In Growing Toe Nail is a common condition involving the great toe. Many surgical procedures have been described. But the problems of recurrence, nail spicules and poor aesthetical consequences remain unresolved and a source of chronic irritation to affected patients.

AIM: The aim of this study is to arrive at the best possible surgical technique for IGTN,having lowest recurrence rate and best aesthetic results.

METHODS: Between July 1995- June 2014, 56 patients (7 with bilateral disease) visiting the outpatient of Department of Surgery of two medical college hospitals were included in the study and were subjected to adequate bilateral para ungual soft tissue excision with nail avulsion. Post-operative bleeding, pain, deformity and recurrence were the factors analysed.

RESULT: Of the 56 cases, 7 had bilateral IGTN (63 nails).The age range was 18-68 years (Mean age 36.28 years). There were 32 Males and 24 females. One case came with reactionary bleeding and one had local injection site inflammation. None had recurrence, any nail spikes or deformity during the mean follow up period of 2.38 years.

CONCLUSION: Para ungual adequate soft tissue excision is an effective technique for the cure of IGTN.

KEYWORDS: Onychocryptosis, in Growing Toe Nail (IGTN), Para Ungula Soft Tissue Excision.

HOW TO CITE THIS ARTICLE: Aswini Kumar Pujahari, Aparajita Mookharjee. "Para Ungula Soft Tissue Excision for in Growing Toe Nail: A Novel Method for Simple Surgical Cure". Journal of Evolution of Medical and Dental Sciences 2015; Vol. 4, Issue 88, November 02; Page: 15279-15282, DOI: 10.14260/jemds/2015/2172.

INTRODUCTION: Onychocryptosis or In Growing Toe Nail (IGTN) is a common clinical problem.[1] It usually affects the great toes in young adult population, possibly because this toe bears the maximum pressure during ambulation (Within the tight confines of the footwear) giving rise to the lateral bulging of the soft tissue much beyond the lateral edge of the nail. Thus the terminal part of the nail at the lateral ends cuts the para-ungual soft tissue which becomes painful, often with pus collection, indicating the need for surgery.[2,3] Except for the patient, it is not considered a major health problem and hence the literature on IGTN is limited.

Surgery is most often required for remission but the rate of recurrences is very high with the definitive risk of poor functional and aesthetical consequences. Among the numerous surgical procedures described in other studies, none is unanimously considered as the most effective.[4]

The conventional surgical approach to IGTN is directed towards the nail, which cuts into the para-ungual soft tissue over a period of time. But in reality, the hard tissue always impinges on to the soft tissue, causes recurrent infection and deformity. (If one cuts the knife with the fruit or fruit with the knife, it is the fruit which always gets cut). In IGTN, all approaches have been towards cutting the knife (The nail) and no approach aimed at dealing with the soft tissue has been described so far.

Financial or Other, Competing Interest: None.

Submission 05-10-2015, Peer Review 06-10-2015,

Acceptance 20-10-2015, Published 30-10-2015.

Corresponding Author:

Dr. Aswini Kumar Pujahari,

Professor, Department of General Surgery,

Vydehi Institute of Medical Sciences and Research Center

Nallurahalli, Bangalore.

E-mail:ashwinipujahari@gmail.com,akpuja@rediffmail.com,

DOI:10.14260/jemds/2015/2172.
This method is directed towards para ungual soft tissue excision for the effective cure of IGTN.

MATERIALS AND METHODS: Cases of painful IGTN with or without sepsis, reporting to surgical outpatient department of two medical college hospitals from July 1995- June 2014 were included in the study. Willing patients above 18 years were included in the study. Patients below the age of 18, unwilling patients and patients with ischemic lower limb were excluded. However controlled DM in patients was not a contraindication for inclusion into study. The whole foot was cleaned with soap and water, including the web space. 5\% Betadine solution was applied as antiseptic preparation. Digital nerve block was used with an equal mixture of $2 \%$ Xylocaine and $0.5 \%$ Bupivacaine, $3-5 \mathrm{ml}$ on either side of the nail.

The whole nail was avulsed. The soft tissue on either side was excised from the margin of nail bed, starting from the tip of the toe towards the germinal matrix side of the nail (Fig-1). The in-growing side was excised more than the non in growing side, thus removing the maximum amount of the infected granulation tissue. In the presence of pus, the eponychium was also excised to avoid pus tracking. Pressure dressing was applied and limb elevated for $30 \mathrm{~min}$ for achieving optimal haemostasis.

After attaining haemostasis the dressing was made loose and then patients were sent home with analgesic and a dose of diazepam at bed time for the first day. No routine antibiotics were used. All subjects received pain killer (Diclofenac 50mg SOS or with maximum of two doses per day) upto a maximum of 5days. All were advised rest with elevation of the limb $\left(15-20^{\circ}\right.$ at the hip with knee at $\left.180^{\circ}\right)$. After 72 hours they were told to soak the dressing in warm salt water at home, remove the dressing, clean with soap and water and apply coconut oil. 
The patients were advised to cover the foot with clean socks till the healing was complete. All the patients were reviewed weekly for first four weeks and subsequently as per the patients need, till the healing was complete. Sixth monthly Follow up was done for recurrence and cosmetic outcome.
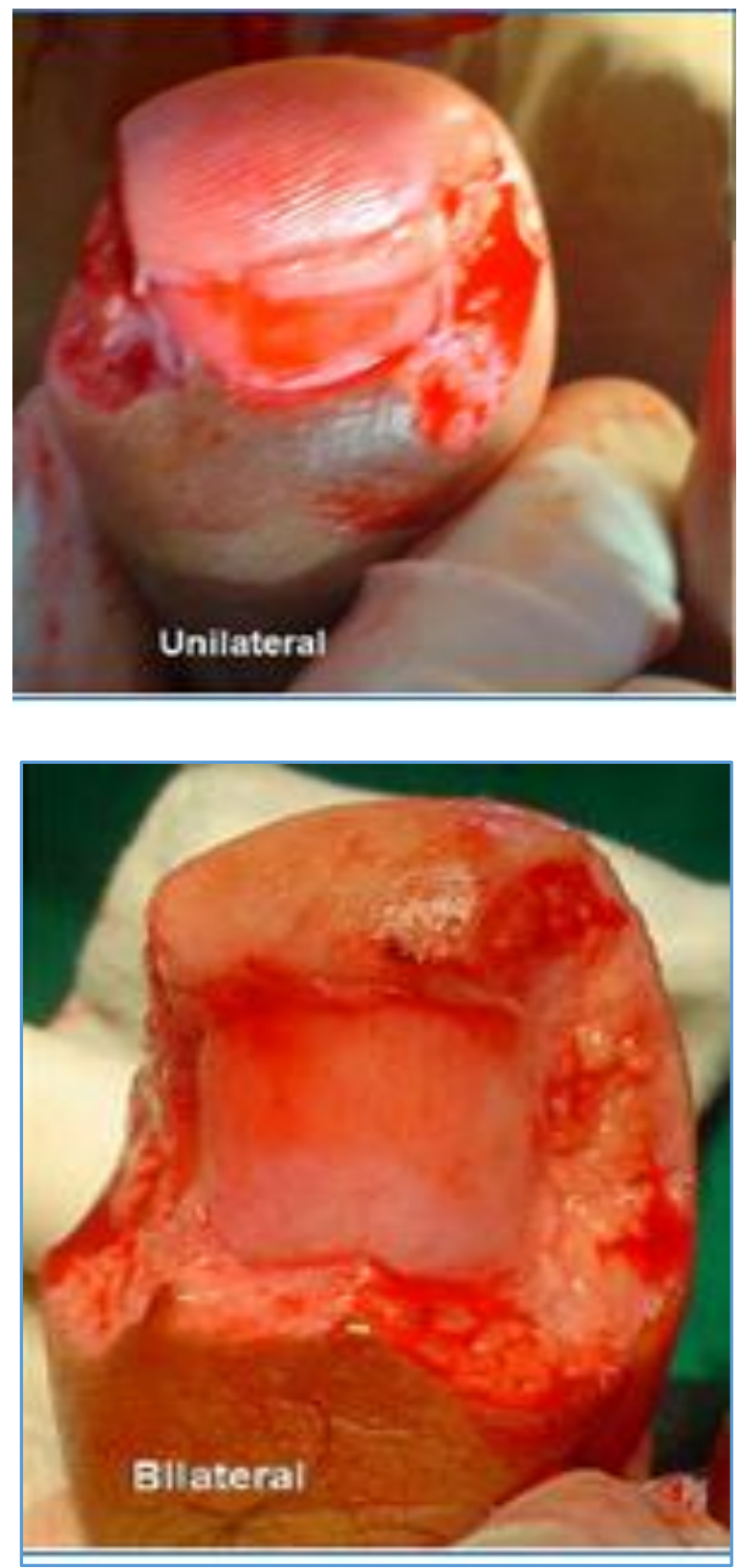

Fig. 1: Image at the end of surgery before the bandaging

RESULTS: There were a total of 56 subjects, including 7 bilateral afflictions (Total 63 nails), with age ranging between 18 and 68 years. 32 patients were males and 24 females. One patient came back in the evening on the day of the surgery with bleeding from operated site. The wound was re-dressed and she was kept overnight in the surgical ward for observation. One lady had redness and swelling at the local injection site.

The same got resolved with oral antibiotics (Amoxycilline+Clavulenic acid) for five days. Pain killer was required for five days to a week, but none required more than 10 tabs. The healing time taken was 4-6 weeks [Fig-2] upto complete growth of new nail. All patients were followed up for minimum of 6 months and maximum upto 12yrs, out of which $52(92.85 \%)$ for 1 year, $40(71.4 \%)$ for 2 years, $8(14.28 \%)$ for 3 years and only one (Author's daughter) for 12 years (Fig-3). There was no appreciable deformity of toes (Fig-3) and none of the patients had any recurrence of IGTN or any ectopic nail spikes at the end of the follow up period.
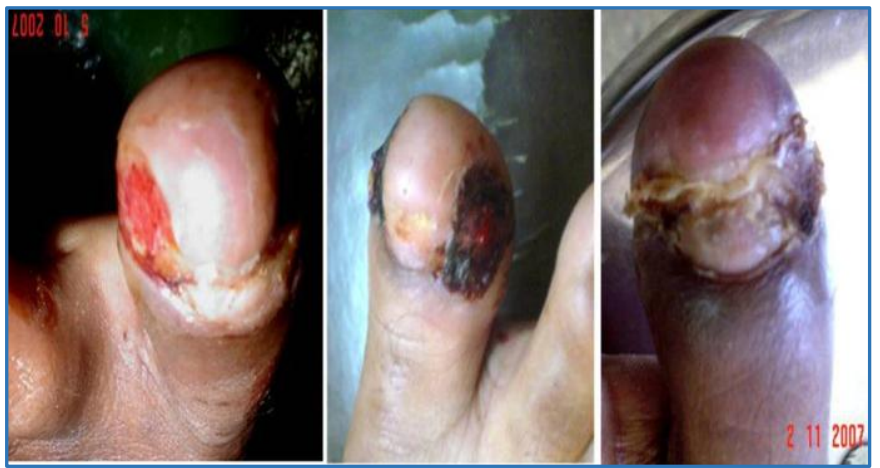

Fig. 2: Three images of a case during weekly follow up

A) first week after surgery.

B) second week after surgery.

C) fourth week after surgery.

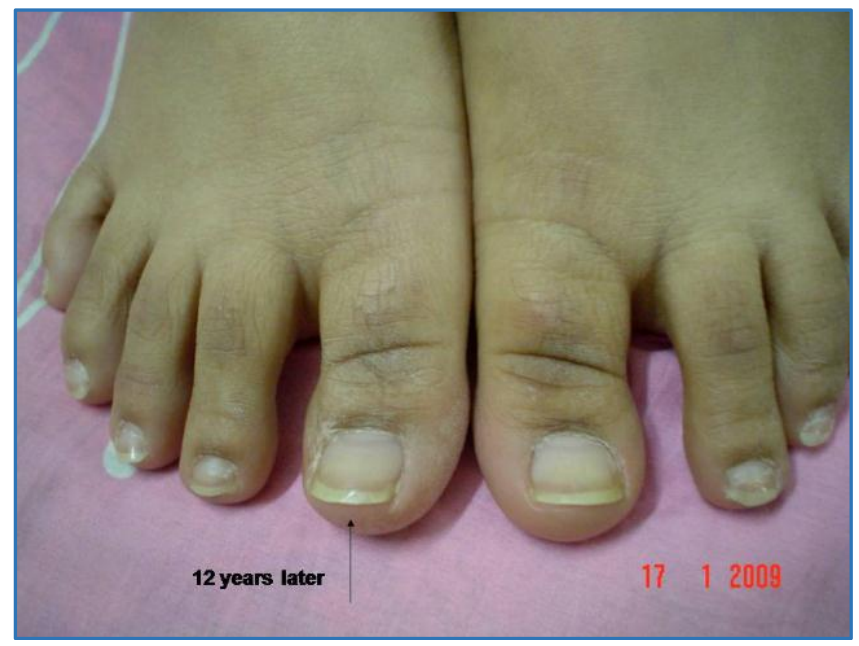

Fig. 3: Image of follow up after 12 years

DISCUSSION: IGTN is a nagging and a painful condition. Most of the nails require some form of surgical procedure for cure.[1] The treatment options available are conservative, nail avulsion, nail matrix surgery and non-nail matrix surgery. Conservative management in young patients can be successfully achieved by health education related to better foot and toe care.[5]

The outcome as well as the duration of therapy are unpredictable with conservative management. Nail avulsion, partial or total, gives temporary relief but results in high recurrence. Nail avulsion alone is inferior to lateral matrix phenolization after avulsion, as reported by Khan et al in their study comparing phenol application after surgery in 2014.[6]

For a long time, the standard surgical method followed for IGTN was avulsion of the lateral side of the nail and cauterization of the germinal matrix with Phenol (Winograd technique) so as to avoid re-growth of the nail on the in-growing side. The average wound healing time was 4-6 weeks. 
It was considered as an excellent surgical method because of its simplicity, low cost, low morbidity, high success rate and quick return to normal activity. ${ }^{[7,8,9]}$ Application of Phenol claimed to reduce the chance of infection as reported by Rounding C et al in 2005.(10) But this has been contradicted by another study by Tilburg et al in 2007 showing high infection rate.[11] Wedge resection of nail matrix and Phenolization is presently reported to have high recurrence and narrowing of the nail plate with consequent disfigurement of the toe in the study by Kose and Guler et al in 2012.[12]

Another study by Grover C et al in 2015, using $10 \%$ $\mathrm{NaOH}$ to destroy the nail matrix instead of phenol, has found to have a better outcome with a mean duration of postoperative pain of 7.92 days and postoperative wound discharge of 15.42 days as compared to application of $88 \%$ Phenol with identical parameters of 16.25 days and 18.13 days respectively. (13)

However, any chemical matricectomy, cannot be definite as it is most likely to be uncontrolled, will either be more or suboptimal. If it is more it will cause soft tissue destruction at the germinal center and eponychium, and in inadequate destruction, ectopic nail or nail spikes will be the outcome.

The rate of occurrence of ectopic nail or spicules may be as low as $0.57 \%$ and seen even after modified matrix advancement flap surgery as observed by Colulu $\mathrm{H}$ et al in 2005.(14) Patients should be aware of these risks before the matrix surgery is performed. A catastrophic case of post phenol burn followed by amputation of the great toe has been reported by Sugden et al in 2001.(15) Any toe loss, that too the great toe is not acceptable for the treatment of IGTN.

It has been further reported by Barclay et al in 2009 that, for postoperative recurrence with pain and infection, the germinal matrix tissue should be permanently destroyed by phenolization (Application of $80 \%-88 \%$ phenol solution), electro-cautery, radiofrequency, or carbon dioxide laser ablation of the nail matrix.[16] This is undoubtedly a very drastic approach for a benign clinical condition.

In one non matrix surgery described as "Knot technique" by Ince B et al in 2015, a wedge excision of the upper and lower soft tissues of the nail was performed and wound margins were simply sutured with $2 / 0$ polypropylene. Approximately 8 to 10 knots were tied under the nail (Needle is passed below the nail) without cutting the stitches. These knots were then used to push the soft tissue down and to raise the nail by pulling up the knots, thereby raising the ingrowing part of the nail.[17] This procedure proved to be too complicated, painful and the knots remaining in situ for a long time was a cause of distress for the patients.

The present procedure requires only two knife strokes and is a simple office procedure done under local anaesthesia in the outpatient department. It is easy to perform even by a general practice doctor because of its flat learning curve. No application of corrosive acid or alkali is the further advantage, to avoid any accident, injury or chronic ulceration. No suture is used, hence is not so painful. Open wound can be considered as a safe wound as far as infection is concerned. There is no nail matrix surgery either partial or complete. No matrix surgery means, no ectopic nail or nail spike.
The healing time is comparable with other techniques, with simple post op home remedies like washing, application of oil and wearing a clean socks. The nails on both the sides remain equal, so cosmetically it is better more so for women. The wide excision of the non in growing side of the nail, and subsequent large raw area are the drawbacks, but after healing, it is cosmetically more appealing (Fig-3). The need for excision of both the para ungual regions is to attain equal healing on both sides and hence uniform growth of nail (As compared with the normal nail) an utmost cosmetic necessity specially for female patients.

CONCLUSION: Para ungual bilateral adequate soft tissue excision, a simple surgery done under local anaesthesia, without any nail matrix interference and use of chemical cauterziation, can be considered as a highly acceptable surgery for IGTN due to its excellent cosmetic outcome and longterm absence of deformity or recurrence.

\section{REFERENCES:}

1. Wollina U. Modified Emmet's operation for ingrown nails using the Er:YAG laser. J Cosmet Laser Ther. 2004; 6:38-40.

2. Bryant A, Knox A. Ingrown toenails: the role of the GP. Aust Fam Physician. 2015; 44: 102-5. PMID: 25770573.

3. Altuntas Z, Kamburoglu HO, Bitik O,Skin bridging secondary to ingrown toenail, Pak J Med Sci. 2014;30:1425-7.doi:10.12669/pjms.306.5790. PMID:25674152].

4. Noël B. Surgery for ingrowing toenails Rev Med Suisse. 2006; 2(63):1104-6, 1109-11.

5. Lazar L,Erez I ,Katz S A. conservative treatment for ingrown toenails in children. Pediatr Surg Int. 1999; 15:121-2.

6. Khan IA, Shah SF, Waqar SH, Abdullali MT, Malik Z, Zahid MA. Treatment of ingrown toe nail-comparison of phenolization after partial nail avulsion and partial nail avulsion alone. J Ayub Med Coll Abbottabad. 2014; 26: 522-5.

7. Bostanci S, Ekmekçi P, Gürgey E. Chemical matricectomy with phenol for the treatment of ingrowing toenail: a review of the literature and follow-up of 172 treated patients. Acta Derm Venereol. 2001; 81:181-3.

8. Thommasen HV,Johnston CS, Thommasen A, The occasional removal of an ingrowing toenail. Can J Rural Med. 2005; 10:173-80.

9. Di Chiacchio $\mathrm{N}^{(1)}$, Di Chiacchio $\mathrm{NG}^{(2)}$. Best way to treat an ingrown toenail. Dermatol Clin. 2015; 33: 277-82. doi: 10.1016/j.det.2014.12.009. Epub 2015 Feb 15. PMID:25828718].

10. Rounding C, Bloomfield S. Surgical treatments for in growing toenails.Cochrane Database Syst Rev. 2005; (2):CD001541.

11. Bos AM, van Tilburg MW, van Sorge AA, Klinkenbijl JH. Randomized clinical trial of surgical technique and local antibiotics for ingrowing toenail. Br J Surg. 2007; 94: 292-6.

12. Kose O, Guler F, Gurcan S, Arik HO, Baz AB, Akalin S. Cosmetic results of wedge resection of nail matrix (Winograd technique) in the treatment of ingrown toenail. Foot Ankle Spec. 2012; 5 (4):241-4. doi: 10.1177/1938640012444729. Epub 2012 Apr 30. PMID: 22547536. 
13. Grover C, Khurana A, Bhattacharya SN, Sharma A. Controlled trial comparing the efficacy of $88 \%$ phenol versus $10 \%$ sodium hydroxide for chemical matricectomy in the management of ingrown toenail. Indian J Dermatol Venereol Leprol. 2015 Sep-0ct;81 (5):472-7. doi: 10.4103/0378-6323.163787. PMID:26323681.

14. Cölolu H, Koçer U, Sungur N, Uysal A, Kankaya Y, Oruç M. A new anatomical repair method for the treatment of ingrown nail: prospective comparison of wedge resection of the matrix and partial matricectomy followed by lateral fold advancement flap. Ann Plast Surg. 2005; 54:306-11.
15. Sugden P, Levy M,Rao GS. Onychocryptosis-phenol burn fiasco. Burns. 2001; 27:289-92.

16. Laurie Barclay. Ingrown Toenail Management Reviewed. Am Fam Physician. 2009;79:303-308.

17. Ince $B$, Dadaci $M$, Altuntas $Z$, Knot technique: a new treatment of ingrown nails. Dermatol Surg. 2015; 41: 2504. doi:10.1097/DSS.0000000000000271.PMID:25627634. 